GMR

\title{
Predicted philogeny, secondary conformational structure, and epitope antigenicity of immunological sequences in poultry
}

L.J. Lara ${ }^{1}$, A.P. Peconick ${ }^{1}$, É.J. Fassani², A.M.P. Júnior ${ }^{1}$, P.R.B. Chalfun ${ }^{1}$, D.L. Raymundo ${ }^{1}$, T.A. Barçante ${ }^{3}$ and J.M. de P. Barçante ${ }^{3}$

${ }^{1}$ Departamento de Medicina Veterinária, Universidade Federal de Lavras, Lavras, MG, Brasil

${ }^{2}$ Departamento de Zootecnia, Universidade Federal de Lavras, Lavras, MG, Brasil

${ }^{3}$ Departamento de Ciências da Saúde, Universidade Federal de Lavras,

Lavras, MG, Brasil

Corresponding author: L.J. Lara

E-mail: lucasjanuzzi@gmail.com

Genet. Mol. Res. 16 (2): gmr16029423

Received October 10, 2016

Accepted March 8, 2017

Published May 18, 2017

DOI http://dx.doi.org/10.4238/gmr16029423

Copyright $(2017$ The Authors. This is an open-access article distributed under the terms of the Creative Commons Attribution ShareAlike (CC BY-SA) 4.0 License.

\begin{abstract}
Poultry production is faced with different types of stresses that are responsible for issues of animal welfare as well as for economic losses. Moreover, the immunity decreases when animals are stressed. In silico analyses are important in reducing the cost and in increasing the accuracy of scientific results. A bioinformatics tool was used to perform ontology studies on 15 different immunological sequences of poultry. The mRNA structures and sequences with maximum antigenic residues were also predicted. No homology was found between the sequences of poultry and mammals. These results helped in the prediction of new potential molecular markers. Of the 15 sequences that were analyzed, predictions could not be made for five because they were longer than 2500 nucleotides; for the remaining 10 sequences, 20 conformational
\end{abstract}

Genetics and Molecular Research 16 (2): gmr16029423 
structures per sequence were predicted and the most stable sequences were identified by their minimum free energy values. The highest antigenic epitopes were accepted by the maximum scores; 15 of the total 8934 epitopes that were predicted were analyzed. These results would aid future studies that use synthetic peptides or recombinants as markers or immunomodulators and would expand our understanding on how stress can modulate the immune system. These would also help in developing rapid diagnostic tools, in increasing animal welfare, biosecurity, and productivity, and also in developing of food additives and environmental enrichment for stress control, thereby, making animal production more sustainable.

Key words: Poultry; Bioinformatics; mRNA; Antigenicity; Epitope; Ontology

\section{INTRODUCTION}

Stress is a common problem in animals and humans. Negative impacts of stress on poultry industry, such as on their production and quality, and the resulting economic losses, have been described for many years (Mashaly et al., 2004; Rozenboim et al., 2007; QuinteiroFilho et al., 2010; de Haas et al., 2013; Lara and Rostagno, 2013). Developed countries, such as the United States, incur costs of 1.69 to 2.36 billion dollars on livestock industry per year because of stress (St-Pierre et al., 2003). The release of catecholamines (norepinephrine and epinephrine) (Lyte et al., 2011; Asano et al., 2012) and glucocorticoids (Sapolsky et al., 2000; Hart and Kamm, 2002) in response to stress involves the hypothalamic-pituitary-adrenal (HPA) axis (Gu et al., 2012). Moreover, studies have shown relationships between the different systems, such as neuroendocrine, immune, and gastrointestinal systems (Ogłodek et al., 2014; Robert and Labat-Robert, 2015) in the response against stress.

Immune response can be divided in two different types, namely the innate and adaptive immune response. Generally, the immune system is able to identify and generate a response against anything that causes an imbalance of the homeostasis, such as pathogens, allergens, or any antigen. Innate immune response is the first to recognize the generic patterns of antigens and it continues until the homeostasis is restored. When the innate response is not able to tackle the imbalance caused by the antigen, the adaptive immune response is initiated and the immunity generated by it confers a memory for this particular antigen (Korver, 2012). It is difficult to understand how the receptors and components of the immune system interact to modulate the immune response against stress. This understanding is crucial for identifying the possibilities for modulating the immunity.

During the last decade considerable progress has been made in the field of molecular biology, especially in the studies on RNA that are crucial to understand as to how the immune components modulate the cells and their mechanisms (Frellsen et al., 2009). The prediction and analysis of the conformational structures of molecules provides new perspectives for the understanding of a molecular pathway. These studies can provide clues about the modulation of stress-mediated imbalance by molecules, such as neurotransmitters and immune peptides. For this purpose, molecular tools are important in predicting the structures of molecules. A number of genetic sequences are deposited each year in the public and private databases from a variety

Genetics and Molecular Research 16 (2): gmr16029423 
of studies. Bioinformatics is an important tool that can help in the organization and analysis of some of the characteristics of these genetic sequences (ontology) and in the prediction of the secondary conformational structure of mRNAs (Kaikabo and Kalshingi, 2008; Römer et al., 2016). The objective of this study was to evaluate the main immune components and predict their ontology and secondary conformational structure. The aim of this study was to find possible immune molecular markers and to preview the binding sites for manipulating, in the near future, synthetic or recombinant peptides that are able to modulate the immune system and to decipher their interactions with other systems so as to regulate the acute and chronic stress suffered by poultry. Furthermore, the knowledge obtained from the present study may be used to determine the requirement of intervention measures against stress and the best time to implement them, as well as in defining the strategic points of management and biosecurity, in addition to the potential therapeutic targets for prevention and treatment of stress.

\section{MATERIAL AND METHODS}

A literature search was performed for identifying the potential molecular markers that could provide a link between the stress response and the immune components (Table 1) using the mRNA from Gallus gallus. The markers derived from the innate and acquired immune response were selected for analysis using computational approaches. To measure the inheritance of the genetic sequences within the species, ontology analyses were done. For all the selected genes, a BLAST search was performed and a phylogenetic tree was constructed. Moreover, for all the selected genes, a prediction of the secondary mRNA was made using an online software (http:// rna.urmc.rochester.edu/RNAstructure Web/Servers/Fold/Fold.html) following the RNA Fold algorithm to predict the lowest free energy conformation (Mathews et al., 2004). Thereafter, we predicted the epitope antigenicity of all the sequences that were searched. Briefly, the nucleotide sequences were translated into protein sequences and then the antigenicity of the epitopes was determined using an Immune Epitope Database Analysis (http://tools.immuneepitope.org/tools/ bcell/iedb_input) following the method of Kolaskar and Tongaonkar (1990).

\begin{tabular}{|c|c|c|c|}
\hline GenBank accession No. & Immune component & Immune response & Query length \\
\hline gi.208964709 & HSP70 & I & 1920 \\
\hline gi.45433513 & IL1 & I & 1107 \\
\hline gi.971376440 & IL1-R & I & 2017 \\
\hline gi.55741695 & IL4 & $\mathrm{A}$ & 411 \\
\hline gi.971419656 & IL4-R & A & 3764 \\
\hline gi.148540095 & IL10 & I & 528 \\
\hline gi. 88853848 & IL10-R & I & 2189 \\
\hline gi.47087194 & IL12 & I & 948 \\
\hline gi.478476198 & IL12-R & I & 2678 \\
\hline gi.45433517 & INF $\gamma$ & I & 1330 \\
\hline gi.62899051 & INF $\gamma$-R & I & 2221 \\
\hline gi.2707470 & $\operatorname{TCR} \gamma \delta$ & $\mathrm{I}, \mathrm{A}$ & 306 \\
\hline gi.71897340 & TLR4 & I & 3532 \\
\hline gi.53854909 & TNF $\alpha$ & I & 674 \\
\hline gi.66793458 & TLR5 & I & 2586 \\
\hline
\end{tabular}

Table 1. Selected mRNA sequences. I (Innate), A (Adaptive), HSP (Heat shock protein), IL (Interleukin), R (Receptor), INF $\gamma$ (Interferon gamma), TNF $\alpha$ (Tumor necrosis factor alpha), TCR $\gamma \delta$ (T cell receptor gamma delta), TLR (Toll like receptor).

Genetics and Molecular Research 16 (2): gmr16029423 


\section{RESULTS AND DISCUSSION}

After the analysis of all the gene sequences using the bioinformatics tools described above, we identified that some genes, such as those of cytokines did not form any phylogenic cluster (Figures S1-S15). The majority of cytokines receptors and toll like receptor (TLR) 4 and 5 had just one root in common, specifically for TLR 4 and 5 because they recognize the same patterns (Leveque et al., 2003; Kogut et al., 2006). Only interleukin (IL) 1 had three genetic clusters and $\mathrm{T}$ cell receptor gamma had six genetic clusters. This can be explained based on the fact that mammals and poultry had different ancestors and they evolved differently. Instead, gene homology can be found for humans and a lack of mammals contributing to the use of same cell molecular marker in different species (Schulpen et al., 2015). The rodents, such as mice and rat, are important models for several human diseases because they have high gene homology and the results obtained in the rodent models can be extrapolated for humans (Huang et al., 2016). It explains the importance of this study where the molecular markers in poultry are so different from that in a common ancestor and demonstrates no homology between the genes.

Depending on the evolutionary distance between the phylogenic clusters, molecular markers described in the literature can be used because domains in the members of a cluster are conserved. However, when the markers do not belong to the same phylogenic cluster the target sequence needs to be checked for possible homology between the studied species in order to increase the accuracy of the molecular marker (Igea et al., 2010). From our perspective, this ontology study was crucial for determining whether we could use the existing molecular markers for the mammalian immune system or we would need to search for potential immune molecular markers specific for poultry. Our results show the importance of selecting the potential immune genes, and of analyzing and testing them for complete understanding of how and which immune response of poultry can be modulated by stress. The interleukin receptor can have the same root as those of the other species because they are more conserved than the soluble interleukins.

Minimum free energy (MFE) analysis (Table 2) revealed a low energy for each mRNA sequence. This suggests that at a controlled temperature $\mathrm{T}\left(310.1 \mathrm{~K}=37^{\circ} \mathrm{C}\right)$ the more stable conformational molecule structure will have the best predicted protein following the central dogma of molecular biology (RNA-Protein) (Jaeger et al., 1989). Among the 15 mRNA sequences, MFE could only be predicted for 10; the remaining five sequences had more than 2,500 nucleotides and could not be analyzed by the software. We determined 200 values of MFE (20 per sequence) and the lowest MFE values were selected (Figures S16-S25) so as to ensure that mRNAs with the most stable secondary structures are studied in the future (Drory Retwitzer et al., 2015; Fu et al., 2015).

The results of our ontology analysis revealed that the sequences identified by us did not have any regions that were conserved in other molecular markers, which have already been studied, highlighting the fact that this is a pioneering study on the structures of nucleotides of genes involved in immunity in poultry. Other studies have shown the prediction of mRNA structure for comprehending the tertiary mRNA structure and the positive or negative impacts of the resulting protein on the organism (Marashi et al., 2006; Frellsen et al., 2009; Bida and Maher, 2012; Contrant et al., 2014) as well as its use in manipulating genetic sequences, for example, to create new recombinant vaccines (Ilyinskii et al., 2009).

Genetics and Molecular Research 16 (2): gmr16029423 
Table 2. Prediction of minimum free energy of mRNA.

\begin{tabular}{l|c|c}
\hline Immune component & Immune response & MFE \\
\hline HSP70 & I & -6337 \\
\hline IL1 & I & -431 \\
\hline IL1-R & I & -5332 \\
\hline IL4 & A & -1261 \\
\hline IL10 & I & -1757 \\
\hline IL10-R & I & -248 \\
\hline IL12 & I & -2976 \\
\hline INF $\gamma$ & I & -6652 \\
\hline INF $\gamma$-R & I & -2078 \\
\hline TNF $\alpha$ & I & \\
\hline
\end{tabular}

MFE (Minimum free energy), I (Innate), A (Adaptive), HSP (Heat shock protein), IL (Interleukin), R (receptor), INF $\gamma$ (Interferon gamma), TNF $\alpha$ (Tumor necrosis factor alpha).

More recently, studies on epitope antigenicity have been performed with the aim of reducing the costs and achieving higher accuracy of new diagnostic platforms. Our antigenicity results (Table 3) and the results shown graphically (Figures S25-S40) revealed a total of 8,934 different antigenic epitopes. The maximum antigenicity score was taken for each sequence/protein. We wanted to get the maximum score for each epitope so as to get the most stable structure of mRNA that would lead to the most antigenic epitope for building our immunodiagnostic platform for assessing stress in poultry. Other studies have shown a high performance using this analysis and the determination of the best antigenic epitope relevant for an immunodiagnostic platform, vaccine production, and several treatments, especially in humans (Kolaskar and Tongaonkar, 1990; Hernández-Guzmán et al., 2014; Cai et al., 2015; Gomez et al., 2015). Such results could start the process for understanding of the immunomodulation caused by stress.

Table 3. Prediction of epitope antigenicity.

\begin{tabular}{|c|c|c|c|c|c|c|}
\hline Immune component & Immune response & Number of epitopes & Position & Residue & Peptide & Score \\
\hline HSP70 & I & 628 & 443 & $\mathrm{~V}$ & SVLVQVY & 1.227 \\
\hline IL1 & I & 195 & 100 & $\mathrm{~F}$ & SAFFLFC & 1.144 \\
\hline IL1-R & $\mathrm{I}$ & 1030 & 16 & $\mathrm{I}$ & AVIICVV & 1.276 \\
\hline IL4 & A & 771 & 712 & $\mathrm{P}$ & VVVPRAV & 1.219 \\
\hline IL4-R & A & 298 & 270 & $\mathrm{P}$ & ALGPVVL & 1.181 \\
\hline IL10 & I & 169 & 7 & A & CCQALLL & 1.236 \\
\hline IL10-R & I & 561 & 237 & $\mathrm{~L}$ & VFVLLIL & 1.251 \\
\hline IL12 & I & 356 & 11 & V & ACCVVLA & 1.281 \\
\hline IL12-R & I & 1861 & 620 & $\mathrm{P}$ & LYIPCVV & 1.258 \\
\hline INF $\gamma$ & I & 158 & 11 & $\mathrm{~L}$ & LFVLSVI & 1.217 \\
\hline INF $\gamma-R$ & I & 561 & 237 & $\mathrm{~L}$ & VFVLLIL & 1.251 \\
\hline TCR $\gamma \delta$ & $\mathrm{I}, \mathrm{A}$ & 642 & 383 & $\mathrm{Y}$ & VICYILV & 1.270 \\
\hline TLR4 & I & 787 & 614 & $\mathrm{~L}$ & ILILVVV & 1.279 \\
\hline TNF $\alpha$ & I & 142 & 121 & I & CCLIPFC & 1.256 \\
\hline TLR5 & I & 775 & 602 & $\mathrm{~L}$ & ILILVVV & 1.279 \\
\hline
\end{tabular}

I (Innate), A (Adaptive), HSP (Heat shock protein), IL (Interleukin), R (Receptor), INF $\gamma$ (Interferon gamma), TCR $\gamma \delta$ (T cell receptor gamma delta), TLR (Toll like receptor), TNF $\alpha$ (Tumor necrosis factor alpha).

\section{CONCLUSIONS}

This study provided 21 mRNA sequences with the highest epitope antigenicity, minimum free energy and specific for poultry which may have a high potential to be an immune molecular marker. Our work limitation is only predicted results, but it is the first 
project on this line and these in silico analysis had low cost compared with in vitro or in vivo experiments. At this point we can go further on this project which may lead an elucidating of stress diagnostic and better understand stress misbalance.

\section{Conflicts of interest}

The authors declare no conflicts of interest.

\section{ACKNOWLEDGMENTS}

Research supported by CAPES (Coordenação de Aperfeiçoamento de Pessoal de Nível Superior), CNPq (Conselho Nacional de Desenvolvimento Científico e Tecnológico) FAPEMIG (Fundação de Amparo à Pesquisa do Estado de Minas Gerais), and UFLA (Universidade Federal de Lavras).

\section{REFERENCES}

Asano Y, Hiramoto T, Nishino R, Aiba Y, et al. (2012). Critical role of gut microbiota in the production of biologically active, free catecholamines in the gut lumen of mice. Am. J. Physiol. Gastrointest. Liver Physiol. 303: G1288-G1295. http://dx.doi.org/10.1152/ajpgi.00341.2012

Bida JP and Maher LJ, 3rd (2012). Improved prediction of RNA tertiary structure with insights into native state dynamics. RNA 18: 385-393. http://dx.doi.org/10.1261/rna.027201.111

Cai Y, Bao J, Lao X, Zheng H, et al. (2015). Computational design, functional analysis and antigenic epitope estimation of a novel hybrid of 12 peptides of hirudin and reteplase. J. Mol. Model. 21: 229. http://dx.doi.org/10.1007/s00894-015-2774-2

Contrant M, Fender A, Chane-Woon-Ming B, Randrianjafy R, et al. (2014). Importance of the RNA secondary structure for the relative accumulation of clustered viral microRNAs. Nucleic Acids Res. 42: 7981-7996. http://dx.doi. org/10.1093/nar/gku424

de Haas EN, Kemp B, Bolhuis JE, Groothuis T, et al. (2013). Fear, stress, and feather pecking in commercial white and brown laying hen parent-stock flocks and their relationships with production parameters. Poult. Sci. 92: 2259-2269. http://dx.doi.org/10.3382/ps.2012-02996

Drory Retwitzer M, Kifer I, Sengupta S, Yakhini Z, et al. (2015). An efficient minimum free energy structure-based search method for riboswitch identification based on inverse RNA folding. PLoS One 10: e0134262. http://dx.doi. org/10.1371/journal.pone.0134262

Frellsen J, Moltke I, Thiim M, Mardia KV, et al. (2009). A probabilistic model of RNA conformational space. PLOS Comput. Biol. 5: e1000406. http://dx.doi.org/10.1371/journal.pcbi.1000406

$\mathrm{Fu} \mathrm{H}$, Yang L and Zhang X (2015). An RNA secondary structure prediction method based on minimum and suboptimal free energy structures. J. Theor. Biol. 380: 473-479. http://dx.doi.org/10.1016/j.jtbi.2015.05.007

Gomez S, Adalid-Peralta L, Palafox-Fonseca H, Cantu-Robles VA, et al. (2015). Genome analysis of Excretory/Secretory proteins in Taenia solium reveals their Abundance of Antigenic Regions (AAR). Sci. Rep. 5: 9683. http://dx.doi. org/10.1038/srep09683

$\mathrm{Gu}$ XH, Hao Y and Wang XL (2012). Overexpression of heat shock protein 70 and its relationship to intestine under acute heat stress in broilers: 2. Intestinal oxidative stress. Poult. Sci. 91: 790-799. http://dx.doi.org/10.3382/ps.2011-01628

Hart A and Kamm MA (2002). Review article: mechanisms of initiation and perpetuation of gut inflammation by stress. Aliment. Pharmacol. Ther. 16: 2017-2028. http://dx.doi.org/10.1046/j.1365-2036.2002.01359.x

Hernández-Guzmán K, Sahagún-Ruiz A, Vallecillo AJ, Cruz-Mendoza I, et al. (2016). Construction and evaluation of a chimeric protein made from Fasciola hepatica leucine aminopeptidase and cathepsin L1. J. Helminthol. 90: 7-13. http://dx.doi.org/10.1017/S0022149X14000686

Huang W, Kazmierczak K, Zhou Z, Aguiar-Pulido V, et al. (2016). Gene expression patterns in transgenic mouse models of hypertrophic cardiomyopathy caused by mutations in myosin regulatory light chain. Arch. Biochem. Biophys. 601: 121-132. http://dx.doi.org/10.1016/j.abb.2016.02.022

Igea J, Juste J and Castresana J (2010). Novel intron markers to study the phylogeny of closely related mammalian species. BMC Evol. Biol. 10: 369. http://dx.doi.org/10.1186/1471-2148-10-369

Genetics and Molecular Research 16 (2): gmr16029423 
Ilyinskii PO, Schmidt T, Lukashev D, Meriin AB, et al. (2009). Importance of mRNA secondary structural elements for the expression of influenza virus genes. OMICS 13: 421-430. http://dx.doi.org/10.1089/omi.2009.0036

Jaeger JA, Turner DH and Zuker M (1989). Improved predictions of secondary structures for RNA. Proc. Natl. Acad. Sci. USA 86: 7706-7710. http://dx.doi.org/10.1073/pnas.86.20.7706

Kaikabo AA and Kalshingi HA (2008). Concepts Of Bioinformatics And Its Application In Veterinary Research And Vaccines Development. Niger. Vet. J. 28: 39-46.

Kogut MH, Swaggerty C, He H, Pevzner I, et al. (2006). Toll-like receptor agonists stimulate differential functional activation and cytokine and chemokine gene expression in heterophils isolated from chickens with differential innate responses. Microbes Infect. 8: 1866-1874. http://dx.doi.org/10.1016/j.micinf.2006.02.026

Kolaskar AS and Tongaonkar PC (1990). A semi-empirical method for prediction of antigenic determinants on protein antigens. FEBS Lett. 276: 172-174. http://dx.doi.org/10.1016/0014-5793(90)80535-Q

Korver DR (2012). Implications of changing immune function through nutrition in poultry. Anim. Feed Sci. Technol. 173: 54-64. http://dx.doi.org/10.1016/j.anifeedsci.2011.12.019

Lara LJ and Rostagno MH (2013). Impact of heat stress on poultry production. Animals (Basel) 3: 356-369. http://dx.doi. org/10.3390/ani3020356

Leveque G, Forgetta V, Morroll S, Smith AL, et al. (2003). Allelic variation in TLR4 is linked to susceptibility to Salmonella enterica serovar Typhimurium infection in chickens. Infect. Immun. 71: 1116-1124. http://dx.doi. org/10.1128/IAI.71.3.1116-1124.2003

Lyte M, Vulchanova L and Brown DR (2011). Stress at the intestinal surface: catecholamines and mucosa-bacteria interactions. Cell Tissue Res. 343: 23-32. http://dx.doi.org/10.1007/s00441-010-1050-0

Marashi SA, Goodarzi H, Sadeghi M, Eslahchi C, et al. (2006). Importance of RNA secondary structure information for yeast donor and acceptor splice site predictions by neural networks. Comput. Biol. Chem. 30: 50-57. http://dx.doi. org/10.1016/j.compbiolchem.2005.10.009

Mashaly MM, Hendricks GL, 3rd, Kalama MA, Gehad AE, et al. (2004). Effect of heat stress on production parameters and immune responses of commercial laying hens. Poult. Sci. 83: 889-894. http://dx.doi.org/10.1093/ps/83.6.889

Mathews DH, Disney MD, Childs JL, Schroeder SJ, et al. (2004). Incorporating chemical modification constraints into a dynamic programming algorithm for prediction of RNA secondary structure. Proc. Natl. Acad. Sci. USA 101: 72877292. http://dx.doi.org/10.1073/pnas.0401799101

Ogłodek E, Szota A, Just M, Moś D, et al. (2014). The role of the neuroendocrine and immune systems in the pathogenesis of depression. Pharmacol. Rep. 66: 776-781. http://dx.doi.org/10.1016/j.pharep.2014.04.009

Quinteiro-Filho WM, Ribeiro A, Ferraz-de-Paula V, Pinheiro ML, et al. (2010). Heat stress impairs performance parameters, induces intestinal injury, and decreases macrophage activity in broiler chickens. Poult. Sci. 89: 19051914. http://dx.doi.org/10.3382/ps.2010-00812

Robert L and Labat-Robert J (2015). Stress in biology and medicine, role in aging. Pathol. Biol. (Paris) 63: 230-234. http:// dx.doi.org/10.1016/j.patbio.2015.07.008

Römer M, Eichner J, Dräger A, Wrzodek C, et al. (2016). ZBIT bioinformatics toolbox: A web-platform for systems biology and expression data analysis. PLoS One 11: e0149263. http://dx.doi.org/10.1371/journal.pone.0149263

Rozenboim I, Tako E, Gal-Garber O, Proudman JA, et al. (2007). The effect of heat stress on ovarian function of laying hens. Poult. Sci. 86: 1760-1765. http://dx.doi.org/10.1093/ps/86.8.1760

Sapolsky RM, Romero LM and Munck AU (2000). How do glucocorticoids influence stress responses? Integrating permissive, suppressive, stimulatory, and preparative actions. Endocr. Rev. 21: 55-89.

Schulpen SH, Theunissen PT, Pennings JL and Piersma AH (2015). Comparison of gene expression regulation in mouseand human embryonic stem cell assays during neural differentiation and in response to valproic acid exposure. Reprod. Toxicol. 56: 77-86. http://dx.doi.org/10.1016/j.reprotox.2015.06.043

St-Pierre NR, Cobanov B and Schnitkey G (2003). Economic Loss from Heat Stress by US Livestock Industries. J. Dairy Sci. 86: 52-77. http://dx.doi.org/10.3168/jds.S0022-0302(03)74040-5

\section{Supplementary material}

Figure S1. Phylogenetic tree of Gallus gallus Heat shock protein.

Figure S2. Phylogenetic tree of Gallus gallus Interleukin 1 beta.

Genetics and Molecular Research 16 (2): gmr16029423 
Figure S3. Phylogenetic tree of Gallus gallus Interleukin 1 beta receptor.

Figure S4. Phylogenetic tree of Gallus gallus Interleukin 4.

Figure S5. Phylogenetic tree of Gallus gallus Interleukin 4 receptor.

Figure S6. Phylogenetic tree of Gallus gallus Interleukin 10.

Figure S7. Phylogenetic tree of Gallus gallus Interleukin 10 receptor.

Figure S8. Phylogenetic tree of Gallus gallus Interleukin 12 receptor.

Figure S9. Phylogenetic tree of Gallus gallus Interleukin 12.

Figure S10. Phylogenetic tree of Gallus gallus Interferon gamma.

Figure S11. Phylogenetic tree of Gallus gallus Interferon gamma receptor.

Figure S12. Phylogenetic tree of Gallus gallus T cell receptor gamma delta.

Figure S13. Phylogenetic tree of Gallus gallus Toll like receptor 4.

Figure S14. Phylogenetic tree of Gallus gallus Toll like receptor 5.

Figure S15. Phylogenetic tree of Gallus gallus Tumor necrosis factor-alpha.

Figure S16. Minimum free energy of Gallus gallus Heat shock protein mRNA.

Figure S17. Minimum free energy of Gallus gallus Interleukin 10 mRNA.

Figure S18. Minimum free energy of Gallus gallus Interleukin 1 receptor mRNA.

Figure S19. Minimum free energy of Gallus gallus Interleukin 1 mRNA.

Figure S20. Minimum free energy of Gallus gallus Interleukin 4 mRNA.

Figure S21. Minimum free energy of Gallus gallus Interleukin 10 receptor mRNA.

Figure S22. Minimum free energy of Gallus gallus Interleukin 12 mRNA.

Figure S23. Minimum free energy of Gallus gallus Interferon gamma mRNA.

Figure S24. Minimum free energy of Gallus gallus Interferon gamma receptor mRNA.

Figure S25. Minimum free energy of Gallus gallus Tumor necrosis factor-alpha mRNA.

Figure S26. Epitope antigenicity of Gallus gallus Heat shock protein.

Figure S27. Epitope antigenicity of Gallus gallus Interleukin 1 receptor.

Genetics and Molecular Research 16 (2): gmr16029423 
Figure S28. Epitope antigenicity of Gallus gallus Interleukin 1.

Figure S29. Epitope antigenicity of Gallus gallus Interleukin 4 receptor.

Figure S30. Epitope antigenicity of Gallus gallus Interleukin 4.

Figure S31. Epitope antigenicity of Gallus gallus Interleukin 10 receptor.

Figure S32. Epitope antigenicity of Gallus gallus Interleukin 10.

Figure S33. Epitope antigenicity of Gallus gallus Interleukin 12 receptor.

Figure S34. Epitope antigenicity of Gallus gallus Interleukin 12.

Figure S35. Epitope antigenicity of Gallus gallus Interferon gamma receptor.

Figure S36. Epitope antigenicity of Gallus gallus Interferon gamma.

Figure S37. Epitope antigenicity of Gallus gallus T cell receptor gamma delta.

Figure S38. Epitope antigenicity of Gallus gallus Toll like receptor 5.

Figure S39. Epitope antigenicity of Gallus gallus Tumor necrosis factor-alpha.

Figure S40. Epitope antigenicity of Gallus gallus Toll like receptor 4. 